\title{
The Brain and the Kidney - Organ Cross Talk and Interactions
}

\author{
Andrew Davenport \\ UCL Center for Nephrology, Royal Free and University College Medical School, London, UK
}

\section{Key Words}

Brain · Kidney • Organ cross talk • Hyponatraemia •

Hypernatraemia

\begin{abstract}
The kidney and the brain play a major role in maintaining normal homeostasis of the extracellular fluid, and as such regulate intracellular volume, by controlling sodium and water balance. However, both hyponatraemic and hypernatraemic states commonly account for acute medical admissions, and also frequently occur during hospital in-patient stays. Both acute and chronic kidney damage can not only affect sodium and water homeostasis, but also the accumulation of uremic toxins; impairs cerebral higher functions and the ability of the brain to adapt to extracellular changes. Acute brain injury, leading to brain stem death, leads to a cytokine storm, inducing inflammation in cadaveric organs used for transplantation, with increased risk of delayed graft function and acute rejection. Copyright $\odot 2008$ S. Karger AG, Basel
\end{abstract}

\section{Normal Physiology}

The brain and the kidney are fundamental for maintaining the homeostatic milieu of the body by regulating body fluid tonicity by adjusting sodium and water balance and volume. Arginine vasopressin $(\mathrm{ADH})$ is synthesised in the supraoptic and paraventricular nuclei as a peptide hormone, which is cleaved from its neurophysin during axonal transport in the posterior pituitary, and secreted following nerve stimulation from the median eminence, floor of the 3 rd ventricle and brain stem. Once secreted, most $\mathrm{ADH}$ is free, with a short half-life of around $10 \mathrm{~min}$, and is cleared by the liver and kidneys. ADH secretion is increased predominantly following an increase in plasma tonicity, which is sensed by hypothalamic osmoreceptors. Increased plasma tonicity also causes a simultaneous increased, but independent, thirst response to drink. The other stimuli to ADH release include hypovolaemia, sensed by baroreceptors in the great vessels and heart [1]. These receptors activate parasympathetic nerves which modify medullary vasocenter activation, leading to $\mathrm{ADH}$ release from the paraventricular nuclei, as $\mathrm{ADH}$ secretion from the supraoptic nucleus only responds to changes in tonicity. Homeostasis is restored by the combination of renal water retention induced by $\mathrm{ADH}$, and the effect of aldosterone by increasing renal sodium retention, and also mobilisation of sodium from body stores, particularly from that bound to proteoglycans in the interstitial matrix, and muscle. ADH is also released by increased sympathetic nervous system activity. There are three main AVP receptors [2], V1a and V1b which signal by inositol phosphate, and V2 receptors which use adenylate cyclase. The V2 receptor is almost exclusively expressed in the basolateral membrane of the renal collecting duct, and activation leads to both increased numbers of aquaporin 2 channels in the apical membrane and also induction of aquaporin 2 channel synthesis, leading

\section{KARGER \\ Fax +4161306 1234 \\ E-Mail karger@karger.ch}

www.karger.com
(C) 2008 S. Karger AG, Basel

0253-5068/08/0266-0526\$24.50/0

Accessible online at:

www.karger.com/bpu
Andrew Davenport

UCL Center for Nephrology, Royal Free and University College Medical School

Hampstead Campus, Rowland Hill Street, London NW3 2PF (UK)

Tel. +44 207794 0500, Fax +442073178591

E-Mail andrew.davenport@royalfree.nhs.uk 
to increased water reabsorption by the kidney [3]. The V1a receptor is found in vascular smooth muscle, and activation, which requires greater plasma levels of $\mathrm{ADH}$ than for V2R activation, causes vasoconstriction with increased systemic blood pressure, and cardiac hypertrophy. There are also Vla receptors in the kidney, and ADH decreases blood flow to the inner medulla by stimulating prostaglandin synthesis, increasing the osmotic gradient and thus renal water reabsorption [1]. In addition, stimulation of V1a receptors in the glomerulus leads to mesangial constriction with reduced glomerular blood flow and reduced proximal tubular filtrate flow, causing increased renal tubular sodium reabsorption. The $\mathrm{V} 1 \mathrm{~b}$ receptor is located in the anterior pituitary, and is involved in the release of ACTH with cortisol-releasing hormone [2].

At the cellular level, in the brain, aquaporin 4 water channels are the main regulatory water channels, and are located at the key regulatory sites controlling water movement between plasma water, cerebrospinal fluid, cerebral interstitial matrix and cerebral neurones and glial cells, particularly astrocytes. Just as AVP regulates aquaporin channels in the renal tubule [3], so in the brain, regulating brain astrocyte water movement. Increased cerebral extracellular tonicity leads to an increase in AVP secretion with increased aquaporin 4 water channels, allowing water to move into the brain to reduce extracellar tonicity and reduce neuronal shrinkage. Conversely, cerebral extracellular hypotonicity leads to reduced AVP with reduced aquaporin channel expression to reduce water movement from plasma into the brain.

\section{Anormal Physiology}

\section{Hyponatraemia}

Serum sodium is a ratio of sodium activity to plasma water and provides no information about total body sodium, and is typically measured using an ion-specific electrode, which assumes that the plasma contains a fixed amount of lipid and protein. Thus, the serum sodium may be reported as artificially low if the plasma contains increased levels of triglycerides, immunoglobulins, glucose mannitol, icodextrin, gelatine and high molecular weight starches used as plasma volume expanders and also lithium, so-called 'pseudohyponatraemia'.

When faced with a patient with hyponatraemia and reduced plasma tonicity, the key examination is that of assessing the extracellular volume [4] (fig. 1). Provided that patients have free access to water, hypovolaemic patients will develop hyponatraemia due to their thirst

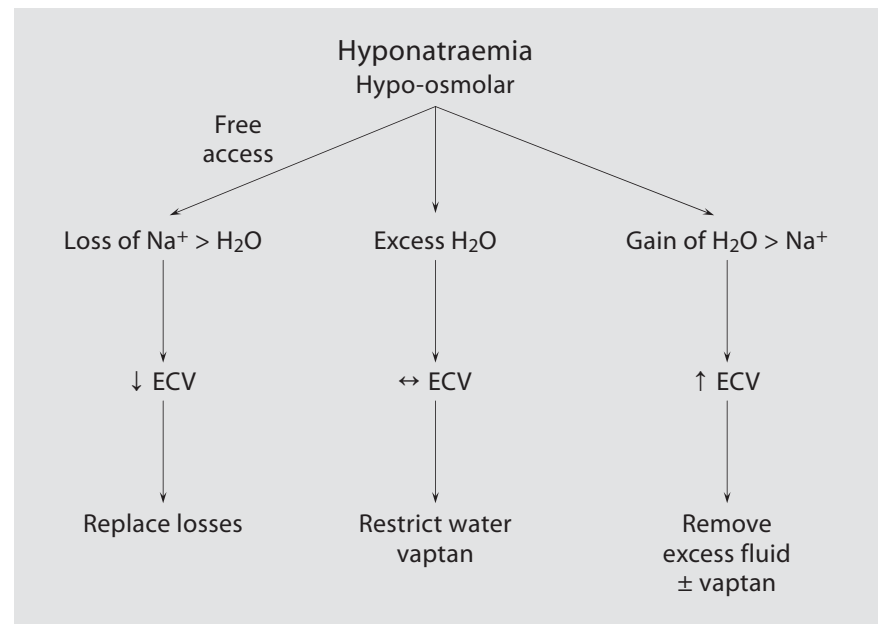

Fig. 1. Basic algorithm for management of patients with hyponatraemic states with hypotonicity. ECV = Extracellular volume.

drive and $\mathrm{ADH}$-induced water retention, as there will be a greater loss of sodium compared to water. This may be due to extra-renal losses, due to excessive sweating, vomiting, diarrhoea, haemorrhage, hyper-osmolar enteral feeds and purgatives (particularly for colonoscopy), fistulae, and also 3rd space fluid sequestration, such as bowel obstruction, peritonitis, pancreatitis, muscle trauma, and burns. Depletion of potassium accompanies many of the conditions which lead to a reduction in extracellular fluid, especially diuretics, and diarrhoeal disease. As the serum sodium is related to the total amount of exchangeable sodium and potassium divided by total body water, a fall in potassium contributes to the development of hypotonic hyponatraemia.

Sodium losses may be secondary to renal disease, particularly renal tubular dysfunction. As patients age, the ability to retain sodium decreases, so elderly patients are more prone to additional sodium losing conditions. Depending upon the severity of the sodium losses and the ability of the patient to compensate in terms of water and sodium replacement, patients may present with hypo- or hypernatraemia. Bartter's syndrome typically presents in early childhood with failure to thrive and lethargy [5], but tetany and seizures may occur both in cases of Bartter's and Gitelman's syndrome due to the combination of hypokalaemia with hypomagnesaemia and/or hypocalcaemia [6]. Bartter's syndrome is associated with reduced sodium reabsorption in the thick ascending loop of Henle of the proximal tubule, and is caused by a channelopathy. The clinical presentation depends upon the underly- 
Table 1. Differential diagnosis of SIADH and cerebral salt wasting (CSW)

\begin{tabular}{lcc}
\hline & SIADH & CSW \\
\hline Serum & & \\
Sodium & $\downarrow$ & $\downarrow$ \\
Uric acid & $\downarrow$ & $\uparrow$ \\
Urea/creatinine ratio & $\leftrightarrow$ & $\uparrow$ \\
Bicarbonate & $\leftrightarrow / \downarrow$ & $\uparrow \uparrow$ \\
Urine & $>25$ & $\uparrow \uparrow$ \\
Sodium & $\uparrow \uparrow$ & $>10 \%$ \\
Osmolality & $<10 \%$ & $\downarrow$ \\
FENa & $\leftrightarrow$ & $\downarrow$ \\
Body weight & $\leftrightarrow$ & \\
ECV & & \\
\hline
\end{tabular}

$\mathrm{FENa}=$ Fractional excretion sodium; ECV = extracellular volume.

ing genetic defect and which of the following channels is affected: sodium-potassium-2-chloride cotransporter, rectifying outer potassium channel, basolateral chloride channel or the sodium chloride cotransporter [5]. Gitelman's syndrome affects sodium transport in the distal tubule, and is due to either a defect in the sodium-potassium-2-chloride cotransporter or the basolateral chloride channel [6]. As chloride channels are present in the striae vesicularis of the inner ear, some patients develop deafness, as sound waves cannot be converted to appropriate electrical impulses. Similarly, other conditions which affect proximal tubular function, causing a proximal (type II) renal tubular acidosis, will also cause increased renal sodium losses. Other causes of renal sodium wasting include renal tubular toxins, such as cases of acetaminophen self-poisoning, and renal tubular damage in the recovering phase of acute tubular necrosis, or diuresis following relief of urinary obstruction. Damage to the renal medulla, following papillary necrosis, and also interstitial nephritis may lead to increased renal sodium losses. Occasionally, patients with polycystic kidney disease, reflux nephropathy and other forms of chronic kidney disease may have increased natriuresis.

Renal sodium losses are also increased in cases of mineralocorticoid deficiency, Addison's syndrome, diuretics and osmotic diuretics (including glucose and ketoacids). Anuric haemodialysis patients given low sodium enteral or parenteral nutrition may become sodium depleted due to the obligate sodium losses in the ultrafiltrate if the dialysate sodium concentration is not adjusted accordingly.
Hyponatraemia with a reduced extracellular fluid volume can also occur in patients with cerebral salt wasting, and sometimes may be confused with the syndrome of inappropriate ADH secretion (SIADH; table 1). Cerebral salt wasting typically occurs after hypothalamic/pituitary surgery and cases of acute intracranial or subarachnoid haemorrhage [7]. It is thought to be due to release of brain-associated natriuretic peptides, with suppressed sympathetic nervous system activity and renin-angiotensin axis, and requires sodium replacement, but typically resolves after a couple of weeks.

Hyponatraemia with a normal extracellular fluid volume is typical of the SIADH, but may also occur in cases of glucocorticoid deficiency and hypothyroidism, and thiazide diuretic therapy in elderly women [8]. The diagnosis of SIADH usually rests on the presence of hypotonic hyponatraemia with an inappropriately high urinary osmolality ( $>100 \mathrm{mosm} / \mathrm{kg} \mathrm{H}_{2} \mathrm{O}$ ), euvolaemia on clinical assessment, with a relatively high urinary sodium (>30 mM) whilst on a normal sodium diet, with absence of renal impairment, diuretics or cortisol or thyroxine deficiency [9]. There are many causes of SIADH (table 2); some drugs increase $\mathrm{ADH}$ release, and others increase the action of ADH.

Hyponatraemia with an expanded extracellular volume may be in association with increased effective arterial blood volume [4], as in cases of acute kidney injury (AKI), chronic kidney disease, and also following rapid or excessive infusion of dextrose-containing fluids or other hypotonic fluids. However, this may also occur when there may be relative arterial underfilling due to reduced cardiac output, or systemic vasodilatation, as in congestive cardiac failure, acute liver failure or cirrhosis, and nephrotic syndrome [10].

The third main cause of hyponatraemia is one of relative water gain, which may occur in primary polydipsia, usually associated with damage to the hypothalamic thirst centre from trauma, infection and granulomatous diseases. Secondary polydipsia is often encountered in psychiatric patients, which may be due to a combination of altered $\mathrm{ADH}$ release to plasma tonicity coupled with increased renal responsiveness and increased thirst due to the local anticholinergic side effects of some of the medications used for therapy. ADH is increased in both long distance runners and methylenedioxy-methamphetamines users, and both groups tend to drink large volumes of water to combat fluid losses due to sweating, resulting in hyponatraemia. Hyponatraemia may also follow surgical procedures, when large volumes of hypotonic fluid have been used for irrigation. Patients may 
suffer seizures and coma following irrigation with glycine- and sorbitol-based solutions. Although this may be due to hyponatraemia, it could also be due to the metabolic products of these organic solutes. Occasionally hyponatraemia develops following tap water enemas, hypoosmolar enteral feeds, or fresh water swimming lessons.

Hypotonic hyponatraemia can lead to seizures, coma, central pontine myelinosis, brain stem herniation and even death. Symptoms are more likely when the fall is abrupt, to $<120 \mathrm{mM}$, and when there is excessive water retention in clinically euvolemic patients, often post-surgical, with primary polydipsia, typically prepubertal children and menstruating women. Cerebral oedema is the main pathological finding [11]. Whereas sodium plays a key role in plasma water and extracellular fluid osmolality, sodium has only a limited intracellular effect. Cells respond to changes in interstitial matrix tonicity initially by changes in electrolyte and osmolyte concentrations. Osmolytes are a series of charged and non-charged small solutes, including amino acids (taurine, betaine, glycine, alaninine, arginine and glutamate), polyalcohols (myoinositol and sorbitol), creatinine and glycerophosphorylcreatinine, which are present in the intracellular cytosol, associated with electrolytes, such as potassium and chloride.

When faced with extracellular hypotonicity and risk of cell swelling due to increased water influx, cells rapidly respond to the fall in tonicity due to water gain by initially transporting sodium, potassium and chloride out of the cell to reduce intracellular tonicity. Later they adapt by transporting osmolytes out of the cells, with accompanying losses of potassium and chloride, through their specific ion channels to maintain size and structure. The regulation of intracellular volume is complex, involving both cell membrane integrins and the intracellular cytoskeleton, resulting in intracellular signalling to both open and/or close ion channels, membrane transporters and regulate gene expression affecting intracellular osmolyte synthesis, such as aldose reductase, or osmolyte uptake by regulating transporter synthesis [12].

Because of the time in lag in cells responding to hypotonic stimuli, by increasing intracellular osmolytes, overzealous correction of serum sodium can exacerbate the situation and precipitate osmotic demyelination. Most cases respond to simple water restriction, and AVP antagonists are now available for treatment (table 1) [2]. However, symptomatic patients need active treatment and should be given careful sodium supplementation, with loop diuretics to prevent expansion of the extracellular volume. There are several formulae to calculate so-

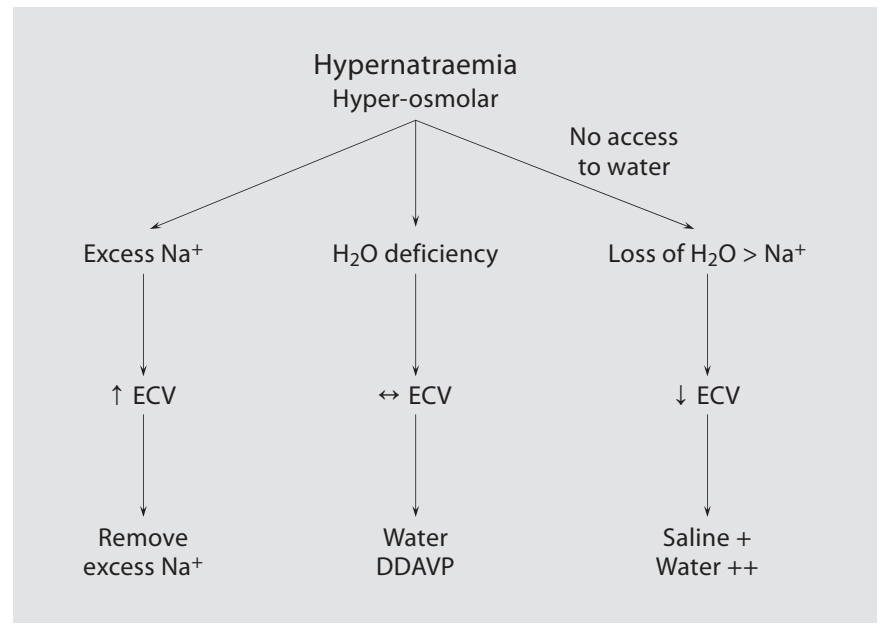

Fig. 2. Basic algorithm for management of patients with hypernatraemic states with hypertonicity.

dium replacement [13], for example the change in serum sodium following 1 litre of infusate $=[($ infusate $\mathrm{Na}+$ infusate $\mathrm{K}$ ) - serum Na]/total body water (litres) +1 .

\section{Hypernatraemia}

Extracellular hypertonicity causes cell shrinkage due to water efflux, as water passes down the diffusion gradient. To protect themselves, the cells increase the concentration of intracellular electrolytes within minutes by actively taking up sodium, potassium and chloride, and then later increase their intracellular osmolytes by increasing synthesis or uptake to maintain intracellular homeostasis. Thus, the brain is particularly vulnerable to developing rebound cerebral oedema from overenthusiastic medical therapy with hypotonic fluids.

Symptoms typically occur in neonates and children, but adults can also develop seizures and coma, particularly when the serum sodium $>160 \mathrm{mM}$. Although more commonly these are associated with too rapid a reduction in plasma tonicity. Severe brain shrinkage can lead to rupture of venous sinuses that become stretched as the brain moves away from the falx and supporting structures.

Hypernatraemia may arise by excessive sodium intake relative to water (fig. 2), following parenteral isotonic and/or hypertonic fluids and hypertonic feeds, particularly in neonates or hospitalised adults who cannot get access to water, and is usually associated with extracellular fluid expansion [14]. Although in the acute situation, such as irrigation of hydatid liver cysts with hyper- 
Table 2. Major causes of SIADH

\begin{tabular}{|c|c|c|c|}
\hline CNS disorders & Drugs/mediators & Cancers & Lung diseases \\
\hline Head trauma & Angiotensin II, thiazides & Leukaemia, lymphoma & Acute respiratory failure \\
\hline $\begin{array}{l}\text { Mass lesions: tumour, abscess sub- } \\
\text { dural }\end{array}$ & $\begin{array}{l}\text { Antipsychotics: haloperidol, } \\
\text { phenothiazines, morphia, nico- } \\
\text { tine, ecstasy }\end{array}$ & $\begin{array}{l}\text { Chest: bronchogenic, mes- } \\
\text { othelioma, thymoma }\end{array}$ & $\begin{array}{l}\text { Infection, abscess, as- } \\
\text { pergillosis, pneumonia, } \\
\text { tuberculosis }\end{array}$ \\
\hline $\begin{array}{l}\text { Inflammation: encephalitis, meningi- } \\
\text { tis, SLE, HIV }\end{array}$ & $\begin{array}{l}\text { Antidepressants: amitriptyline, } \\
\text { fluoxetine (other SSRIs), MAOIs }\end{array}$ & $\begin{array}{l}\text { Gastrointestinal: pharynx, } \\
\text { stomach, duodenum, pan- } \\
\text { creas }\end{array}$ & $\begin{array}{l}\text { Chronic pulmonary } \\
\text { obstructive disease }\end{array}$ \\
\hline $\begin{array}{l}\text { Demyelination: Guillain Barré, mul- } \\
\text { tiple sclerosis, spinal cord lesions }\end{array}$ & $\begin{array}{l}\text { Anti-epileptics: carbamezepine, } \\
\text { barbiturates, valproate }\end{array}$ & $\begin{array}{l}\text { Genitourinary: bladder, } \\
\text { prostate, ureter, uterus }\end{array}$ & $\begin{array}{l}\text { Positive pressure ventila- } \\
\text { tion }\end{array}$ \\
\hline Stroke & Bradykinin & Ewing sarcoma & Cystic fibrosis \\
\hline Haemorrhage & Chlorpropamide & & Pneumothorax \\
\hline Pituitary stalk section & $\begin{array}{l}\text { Clofibrate, } \\
\text { lansoprazole }\end{array}$ & & \\
\hline Acute psychosis, porphyria & $\begin{array}{l}\text { Cytotoxics: cyclophosphamide, } \\
\text { ifosfamide, vinblastine, vincris- } \\
\text { tine }\end{array}$ & & \\
\hline Delirium tremens & $\begin{array}{l}\text { Histamine } \\
\text { Midrodine } \\
\text { Narcotics: opoid } v \text { agonists } \\
\text { Nicotine } \\
\text { ADH analogues: desmopressin, } \\
\text { oxytocin }\end{array}$ & & \\
\hline
\end{tabular}

CNS = Central nervous system; SLE $=$ systemic lupus erythematosus.

tonic saline, extracellular volume expansion may not be discernable. Cushing's syndrome and primary hyperaldosteronism may also lead to hypernatraemia due to net sodium gain.

The majority of cases of hypernatraemia are due to a relatively greater loss of water than sodium, and can be caused by intrinsic renal disease, the polyuric phase of recovering acute tubular necrosis, post-obstructive diuresis, and following diuretics and osmotic diuretics. Nonrenal causes include gastrointestinal losses due to vomiting, naso-gastric drainage, enteric fistulae, diarrhoea, and osmotic or other purgatives. Hypernatraemia may also develop in patients with burns and excessive sweating.

Hypernatraemia with pure water loss is associated with a reduction in the extracellular volume, but this is usually undetectable clinically. The two main causes relate to cranial diabetes insipidus and nephrogenic diabetes insipidus (table 3 ), either due to a reduction in brain $\mathrm{ADH}$ release or a failure of $\mathrm{ADH}$ to act in the kidney [14,
15]. Most cases of nephrogenic diabetes insipidus are acquired, although two inherited forms are recognised, one an X-linked condition affecting the V2 receptor, the other a recessive condition affecting the aquaporin 2 gene. However, a number of patients, particularly elderly, may have altered thirst perception and be unable to freely access water, or have an altered osmostat.

As with the treatment of hyponatraemia, the key to success is to correct plasma tonicity slowly and to address the underlying or precipitating condition.

Patients with cerebral diabetes insipidus respond to vasopressin analogues, and even those with nephrogenic diabetes insipidus may have some response [15].

In symptomatic patients, then, an increase in serum sodium of $1 \mathrm{mmol} / \mathrm{h}$ may be acceptable if the hypernatraemia is known to be acute $(<48 \mathrm{~h})$; whereas if longer standing then a much slower correction is required to prevent rebound cerebral oedema. As the risk of cerebral oedema is increased by increased infusate volume, a 
Table 3. Causes of hypernatremia due to diabetes insipidus

\begin{tabular}{ll}
\hline Cranial diabetes insipidus & $\begin{array}{l}\text { Nephrogenic diabetes } \\
\text { insipidus }\end{array}$ \\
\hline Head trauma & $\begin{array}{l}\text { Genetic: X linked (V2 re- } \\
\text { ceptor), autosomal reces- } \\
\text { sive (aquaporin } 2 \text { receptor) }\end{array}$
\end{tabular}

Post-operative: hypophysectomy, craniopharyngioma, hypothalamic tumours

Brain stem tumours: dysgerminoma, craniopharyngioma, suprasellar pituitary tumour, metastatic tumours (breast, lung, leukaemia, lymphoma)

Infections: encephalitis, meningitis, tuberculosis, syphilis

Congenital: vasopressin V2 receptor mutations

Chronic kidney disease, polycystic kidney disease, medullary cystic kidney disease, pyelonephritis, obstructive kidney disease

Drugs: lithium, demeclocycline, amphotericin, methoxyflurane, foscarnet, cidofovir, loop diuretics, osmotic diuretics, glucose and/or saline-induced diuresis, vasopressin antagonists

Vascular causes: intracranial aneurysms, Sheehan's syndrome, cerebrovascular accident, brain stem hypoxia

$\begin{array}{ll}\begin{array}{l}\text { Granulomatous disease: sarcoid- } \\ \text { osis, histiocytosis X, Wegener's } \\ \text { granulomatosis }\end{array} & \begin{array}{l}\text { Granulomatous disease: } \\ \text { sarcoidosis }\end{array}\end{array}$
granulomatosis

\begin{tabular}{ll}
\hline $\begin{array}{l}\text { Autoimmune: SLE, vasopressin } \\
\text { antibodies }\end{array}$ & $\begin{array}{l}\text { Autoimmune: Sjögren's } \\
\text { disease }\end{array}$ \\
\hline Ideopathic & Gestational DI \\
\hline
\end{tabular}

Anorexia nervosa, alcohol, cor- Primary polydipsia rection of SVT, acute fatty liver

Genetic: autosomal dominant, autosomal recessive (DIMOAD)

Electrolyte induced: hypokalaemia, hypercalcaemia

slowly infused hypotonic solution is far preferable to isotonic saline [16]. The change in serum sodium following 1 litre of infusate $=[($ infusate $\mathrm{Na}+$ infusate $\mathrm{K})-$ serum $\mathrm{Na}] /$ total body water (litres) +1 .

\section{Effect of AKI on the Brain}

Patients with AKI are more susceptible to encephalopathy than those with chronic kidney disease, as there is less time to adapt to uraemia. The initial clinical symp-

toms and signs are fatigue, poor concentration, and clumsiness, which progress to asterixis, multifocal myoclonic jerks, generalised seizures, confusion and eventual coma. In part, these findings are due to changes in both body sodium and water balance [17], other electrolyte abnormalities [18], and also the acute accumulation of uremic toxins, including guanidine compounds, creatinine, guanidine-succinic acid, and methylguanidine, which modulate nitric oxide synthase [19], and changes in free amino acids and neurotransmitters. In addition, the inflammatory effects of AKI are not only limited to the kidney, but can also lead to inflammatory effects in other organs, including the brain. Recent animal experiments have shown that AKI leads to inflammation within the hippocampal region of the brain, associated with neuronal death in the cornu ammonis within the hippocampus [20]. The hippocampus is part of the limbic system, and plays an important role in memory and learning, and also in emotions such as anxiety and depression [21]. This part of the brain is vulnerable to cerebral ischaemia, and other models of global cerebral ischaemia and/or hypoxia with reperfusion have shown increased neuronal death and inflammation in the cornu ammonis [22]. In addition, AKI resulted in generalised astrocyte activation throughout both the cortex and corpus callosum, with corresponding increased cerebral pro-inflammatory mediators. Activation of astrocytes leads to the release of the calcium-binding protein $S 100 \beta$, which is used as a biomarker of brain damage, particularly in cases of systemic sepsis and hypoxic brain injury [23]. Other biomarkers of cerebral injury include neurone-specific enolase. The permeability of the blood-brain barrier increases following acute bilateral nephrectomy in mice, but cerebral oedema only developed following severe AKI, due to renal ischaemia followed by reperfusion [20]. This would suggest that the degree of cerebral injury depends not only on AKI per se, but also the etiology of the AKI, and that those causes which cause direct cerebral endothelial damage or marked systemic inflammation are much more likely to lead to cerebral oedema and clinical encephalopathy [23].

There are an additional series of conditions that can acutely affect both the brain and the kidney, including thrombotic thrombocytopenic purpura, characterised by a reduced metalloproteinase ADAMTS-13, allowing the release of large multimers of von Willebrand factor by activated endothelial cells, leading to platelet microthrombi and an occlusive microangiopathy. Both primary vasculitides (polyarteritis nodosa, Wegener's granulomatosis, microscopic polyangiitis, systemic lupus erythe- 
matosus and Churg Strauss syndrome) and secondary vasculitis, associated with infections, malignancy, toxins and drugs, may have neurological presentations with seizures, generalised encephalopathy, and/or posterior leukoencephalopathy [24]. Sarcoid and Wegener's granulomatosis may cause cranial nerve palsies, and pituitaryhypothalamic dysfunction.

\section{Effect of Chronic Kidney Disease on the Brain}

\section{Chronic Kidney Disease}

Uremic encephalopathy is an organic brain syndrome [25] which occurs in patients with chronic kidney disease stage 5 , typically following a sudden decrease in residual renal function precipitated and/or exacerbated by hypertension, electrolyte imbalances, drugs or toxins. Hypertension often leads to a reversible posterior leukoencephalopathy syndrome, with vasogenic oedema developing in and around the brain stem [24]. As the subtentorial compartment of the brain has very limited expansion, only a relatively small degree of oedema is required to compress the brain stem and induce coma. This syndrome is more commonly found in patients with systemic lupus erythematosus and liver failure. Both hyper- and hyponatraemia can precipitate encephalopathy in chronic kidney disease patients, as can hypercalcaemia and hypermagnesaemia. Drugs which accumulate in chronic kidney disease, including penicillin and cephalopsporin antibiotics and antiviral agents, acyclovir, gancicolvir and foscarnet, can similarly precipitate encephalopathy [26]. Heavy metals, aluminium and other toxins can accumulate and lead to encephalopathy in these patients due to reduced renal excretion [27].

In addition, there are conditions which affect both the kidney and the brain, including methylmalonic acidemia, which causes chronic kidney disease due to renal tubular damage, and also cerebral cognitive changes, asterixis and eventually coma, and Fabry's disease, with glomerular damage, and cerebral infarcts with loss of cognitive function and dementia. Adult polycystic kidney disease, von Hippel-Lindau disease and tuberous sclerosis may similarly cause chronic kidney disease and subarachnoid or intracranial brain haemorrhage.

Initially symptoms are non-specific, with fatigue, apathy, impaired higher cognitive functions, and formal testing may demonstrate abnormal evoked potentials following visual flash stimuli, with delayed P3 and N3 latency and amplitude [28]. Patients progress to confusion, through to coma. Motor function is often abnormal, with resting tremor, asterixis and myoclonic jerks, which may progress to generalised tonic-clonic seizures. Electroencephalographic recordings typically show a preponderance of slow wave activity, $\delta$ - and $\Phi$-waves, over the frontal lobes, with reduced normal $\alpha$ - and $\beta$-waves.

The pathophysiology of uremic encephalopathy is complex and remains poorly understood [25]. Contributing factors include: accumulation of metabolites, hormonal disturbances, altered intermediatory metabolism, and imbalances in excitatory and inhibitory neurotransmitters. In renal impairment, urea, guanidino compounds, uric acid, hippuric acid, various amino acids, polypeptides, polyamines, phenols, phenolic and indolic acids, acetone, glucuronic acid, carnitine, myoinositol, sulphates, phosphates and 'middle molecules' all accumulate and may possibly act as uremic neurotoxins, but no single metabolite has been identified as the only cause of uraemia [29]. However, removal of these uremic toxins by dialytic treatments and/or renal transplantation is associated with an improvement in uremic encephalopathy, thus supporting a pathophysiological role. Guanidine compounds are markedly increased in serum, cerebrospinal fluid and the brain of uremic patients, and it has been postulated that these compounds have excitatory effects on the central nervous system by activation of the excitatory N-methyl-D-aspartate receptors and concomitant inhibition of inhibitory GABA-ergic neurotransmission [30]; in addition, demyelination may occur both in the central and the peripheral nervous system, as retention of guanidinosuccinic acid causes inhibition of the transketolase enzyme, which plays a vital role in the maintenance of myelin.

In uremic animal and in vitro studies, intermediary metabolism is affected, with increased levels of creatine phosphate, adenosine triphosphate and glucose, and decreased levels of monophosphate, adenosine diphosphate and lactate. These biochemical changes are associated with a reduced metabolic rate of the brain and a decrease in cerebral oxygen consumption [31]. In addition, hormonal disturbances have been suggested to play a role in the pathogenesis of uremic encephalopathy. For example, the calcium content of the cerebral cortex is almost twice that of the normal brain. This increase is probably due to secondary hyperparathyroidism, as both electroencephalographic abnormalities and brain calcium accumulation could be prevented by parathyroidectomy in dog experiments of acute and chronic kidney failure [18].

As with any chronic health condition, depression is common amongst patients with chronic kidney disease [32]. Sleep patterns are often affected in patients with 
chronic kidney disease, with an increased risk of sleep apnoea. Sleep disturbances are often associated with restless legs, implicating uremic toxicity, which is supported by improvement in symptoms and sleep studies following renal transplantation or implementation of more frequent and prolonged haemodialysis sessions [33]. Appetite is often depressed in patients with chronic kidney disease, and as residual renal function is lost patients typically reduce dietary protein intake. These effects may be related to increases in circulating leptin and ghrelin, hormones which are involved in controlling satiety, and therefore suppress appetite. Other studies have reported disorders of the hypothalamic pituitary axis and thyroid function in patients with chronic kidney disease, which typically resolve post-renal transplantation or intensive haemodialysis [34]. Prolactin levels rise in chronic kidney disease and may cause breast tissue enlargement in males and even rarely galactorrhoea.

In addition, higher mental functions, as assessed by psychometric testing, are typically decreased compared to those predicted from educational and social background, even in patients adequately dialysed by both peritoneal and haemodialysis [35]. Typically, following successful kidney transplantation, patients improve, with lower depression and higher psychometric scores [36], supporting a pathogenetic role for uremic toxins. However, in patients treated by haemodialysis for more than 4 years, there was no improvement in psychometric performance [35]. This would suggest that either other conditions affecting the brain, such as cerebrovascular disease, cause permanent irreversible structural damage to the brain, or that dialysis per se predisposes to cerebral injury.

Pre-existing cerebrovascular disease is prevalent in chronic kidney disease patients, with reports of 18 and $13.7 \%$ of patients starting dialysis in the United States and Europe having a history of stroke, transient ischaemic attack or carotid endarterectomy [37].

Comorbid conditions such as hypertension, diabetes and hyperlipidaemia, which are known risk factors of cerebrovascular disease in the general population, are common in patients with chronic kidney disease. However, in uremic patients the pathogenesis of vascular disease may be somewhat different from the general population due to the high prevalence of non-traditional risk factors such as disturbances in the calcium $\times$ phosphate product, inflammation, hyper-homocysteinaemia, and oxidative stress [38]. Small lacunar brain infarcts are the most common finding at postmortem, in keeping with small vessel hypertensive disease. Blood pressure control is often not optimal in dialysis patients [39], and in addition repeated episodes of intradialytic hypotension may lead to irreversible brain ischaemia [40] and water-shed cerebral infarcts. Thus, the persistent loss of higher mental functions in the long-term dialysis patients is probably due to repetitive cerebral ischaemia injury.

\section{Effects of Haemodialysis on the Brain}

Plasma tonicity increases in chronic kidney disease, and therefore to compensate for this, cerebral neurones and astrocytes increase their osmolyte concentrations [17]. During rapid haemodialysis, there is an abrupt reduction in plasma water tonicity due to urea removal. As urea transport through cell membranes is limited by urea transporters, this leads to a urea concentration gradient between the plasma water and both the cerebrospinal fluid and cerebral interstitium. As water transport through aquaporin channels is much faster than that of urea, water passes along the concentration gradient back into the brain [17] and is predominantly taken up by astrocytes, causing brain swelling. This is exacerbated by the increased osmolyte content of these cells; although urea moves relatively quickly across astrocyte cell membranes, other osmolytes, particularly those which rely on organic acid transporters, such as hippurate and 3-carboxylmethyl-5-propyl-2-furanoproprionate indoleacetate, can only leave the cell relatively slowly [41] as in chronic kidney disease the organic acid exchanger is inhibited by taurine and other compounds. Thus, the brain swells even following a standard outpatient haemodialysis session. Surprisingly, most patients suffer minimal effects, complaining of lethargy and occasional headache. However, in paediatric practice, but also in patients with AKI and/or head injury, patients may fit post-dialysis due to this dialysis disequilibrium syndrome. Care is therefore required to adjust the dialysis prescription to minimise changes in plasma tonicity during haemodialysis treatment to prevent at-risk patients from becoming symptomatic [42].

At the start of haemodialysis, cerebral blood flow is either normal or decreased in patients with chronic kidney disease, but regional cortical oxygen delivery is reduced, even in non-anaemic patients [43]. Many haemodialysis patients are elderly, and middle cerebral artery blood flow decreases with age [44]; additionally, as ultrafiltration increases, middle cerebral blood flow falls. However, cerebral blood flow has been shown to respond appropriately to changes in arterial carbon dioxide tensions during dialysis. During dialysis, carbon dioxide levels fall, with an increase in bicarbonate, and this leads 
to a change in $\mathrm{pH}$ in the medullary respiratory centre, with changes in respiratory drive typified by hypoventilation and respiratory pauses towards the end of the dialysis session. Episodes of intradialytic hypotension would cause a reduction in cerebral blood flow, followed by a reactive local vasodilatation to the ischaemic insult. This reactive vasodilatation leads to an increase in intracranial blood volume, cerebral volume, and oedema [45]. Thus, hypotension during dialysis exacerbates the tendency to develop cerebral swelling and should be avoided [46].

The kidney plays a pivotal role in excreting toxins and heavy metals [27]. Thus, patients with chronic kidney disease are at increased risk of heavy metal poisoning and other toxins. During haemodialysis the patient is exposed to hundreds of litres of dialysate water, and therefore contaminants in the dialysate water can potentially diffuse into the patient. Aluminium contamination of domestic water is the classic example of a dialysate contaminant that accumulates in haemodialysis patients, leading to a characteristic pseudo-parkinsonian neurological syndrome [47] characterised by micrographia, dysarthria with a stuttering speech, dysphasia, dyspraxia, bent posture, shuffling gait, myoclonic jerks which may transgress to multifocal seizures, progressive dementia and finally death [48]. How aluminum interferes with neuronal function to cause dementia remains to be elucidated, although it does impair microtubular function and may also reduce calmodulin activity via binding and reduced neurotransmitter uptake.

Wernicke's encephalopathy can develop in haemodialysis patients due to the combination of reduced thiamine intake and increased losses, particularly when intensive dialysis is used in malnourished patients [46]. The classic triad of opthalmoplegia, ataxia, and cognitive symptoms, including confabulation and/or disturbances of consciousness, is rarely present, and because of similarities with uremic encephalopathy, this disorder often remains unrecognised with resultant high fatality.

\section{Renal Transplantation and the Brain}

Successful renal transplantation alleviates the uremic component, and most patients improve cognitively. However, immediately after cadaveric transplant reperfusion, there is a marked cytokine storm, which can cause generalised encephalopathy with fitting and/or posterior leukoencephalopathy, particularly in association with hypertension and calcineurin inhibitors. Some of the monoclonal antibody immunosuppressant agents which target lymphocytes, including OKT3, anti-CD25 and
CAMPATH-1, by causing cytokine release can also precipitate encephalopathy and/or aseptic meningism. During the first 3 months following transplantation when immunosuppressant doses are at their highest, patients can develop opportunistic infections by reactivating dormant viruses, bacteria, metazoan and protozoan parasites or contracting de-novo infections, such as Listeria monocytogenes and invasive fungal infections [49]. Reactivation of the JC polyoma virus leads to a progressive multi-focal leukoencephalopathy, which can lead to a rapid downhill clinical course with dementia and ataxia, leading to a vegetative state [50]. In addition, there is an increased incidence of post-transplant lymphoproliferative disease, particularly Epstein-Barr-associated lymphomas, which may be multifocal with both intracerebral and intrarenal lesions.

\section{Effect of Acute Brain Injury on the Kidney}

When patients suffer irreversible brain injury, they may not only become polyuric, but brain death is associated with a marked catecholamine and cytokine release, or so-called cytokine storm, with increased circulating levels of inflammatory mediators, including IL-6, IL-10, TNF $\alpha$, TGF $\beta$, MIP- $1 \alpha$. Thus, the kidneys harvested from patients with brain stem death who become cadaveric organ donors are affected by this inflammatory milieu [51]. It has been recognised for some time that whereas HLA matching is important for the success of cadaveric transplantation, it is not so relevant in live unrelated renal transplantation, due to the reduced ischaemia and reperfusion injury to the kidney to be transplanted. The cytokine storm associated with brain death leads to upregulation of both HLA class I and II expression in the cadaveric kidney, with corresponding increased inflammatory cell migration into the cadaveric kidney [52]. Thus, following ischaemia during organ retrieval, and then reperfusion at the time of transplantation, a much greater inflammatory response occurs with the cadaveric transplant, resulting in both increased risk of organ rejection, but also delayed graft function.

\section{Acknowledgement}

I wish to thank Paul Sweny for his support over the past decade. 


\section{References}

1 Robertson GL: Physiology of ADH secretion. Kidney Int Suppl 1987;21:S20-S26.

2 Decaux G, Soupart A, Vassart G: Non-peptide arginine-vasopressin antagonists: the vaptans. Lancet 2008;371:1624-1632.

-3 Agre P: Aquaporin channels in the kidney. J Am Soc Nephrol 2000;11:764-777.

-4 Schrier RW: Pathogenesis of sodium and water retention in high output and low output cardiac failure, nephritic syndrome, cirrhosis and pregnancy. N Engl J Med 1988;319: 1065-1072 and 1127-1134.

-5 Bartter FC, Pronove P, Gill JR Jr, MacCardle RC: Hyperplasia of the juxtaglomerular complex with hyperaldosteronism and hypokalemic alkalosis. A new syndrome. 1962. J Am Soc Nephrol 1998;9:516-528.

-6 Bettinelli A, Tedeschi S: Hypokalemia and hypomagnesemia of hereditary renal tubular origin. Bartter and Gitelman syndromes. Acta Biomed 2003;74:163-167.

7 Atkin SL, Coady AM, White MC, Mathew B: Hyponatremia secondary to cerebral salt wasting syndrome following routine pituitary surgery. Eur J Endocrinol 1996;135: 245-247.

8 Lien YH, Shapiro JL: Hyponatremia: clinical diagnosis and management. Am J Med 2007; 120:653-658.

$\checkmark 9$ Gross P: Treatment of hyponatremia. Intern Med 2008;47:885-891.

10 Davenport A: Ultrafiltration in diuretic resistant volume overload in nephritic syndrome and patients with ascites in chronic liver disease. Cardiology 2001;96:190-195.

11 Arieff AI, Ayus JC, Fraser CL: Hyponatremia and death or permanent brain damage in healthy children. BMJ 1992;304:1218-1222.

12 Chesney RW: The role of the kidney in protecting the brain against cerebral edema and neuronal cell swelling. J Pediatr 2008;152: 4-6.

13 Androgue HJ, Madias NE: Hyponatremia. N Engl J Med 2000;342:1581-1589.

14 Lok JA, Verbates JG: Disorders of water and salt metabolism associated with pituitary disease. Endocrinol Metab Clin North Am 2008;37:213-234.

15 Ball SG: Vasopressin and disorders of water balance: the physiology and pathophysiology of vasopressin. Ann Clin Biochem 2007; 44:417-431

16 Androgue HJ, Madias NE: Hypernatremia. N Engl J Med 2000;342:1493-1499.

-17 Arieff AI, Massry SG, Barrientos A, Kleeman CR: Brain water and electrolyte metabolism in uremia: effects of slow and rapid hemodialysis. Kidney Int 1973;4:177-187.

18 Arieff AI, Massry SG: Calcium metabolism of brain in acute renal failure: effects of uremia, hemodialysis, and parathyroid hormone. J Clin Invest 1974;53:387-392.
19 De Deyn PP, Vanholder R, D’Hooge R: Nitric oxide in uremia: effects of several potentially toxic guanidino compounds. Kidney Int Suppl 2003;84:S25-S28.

20 Liu M, Liang Y, Chigurupati S, Lathia JD Pletnikov M, Sun Z, Crow M, Ross CA, Mattson MP, Rabb H: Acute kidney injury leads to inflammation and functional changes in the brain. J Am Soc Nephrol 2008;19:13601370.

21 Heldt SA, Stanek L, Chhatwal JP, Ressler KJ: Hippocampus-specific deletion of BDNF in adult mice impairs spatial memory and extinction of aversive memories. Mol Psychiatry 2007;12:656-670.

22 White BC, Sullivan JM, DeGracia DJ, O’Neil BJ, Neumar RW, Grossman LI, Rafols JA, Krause GS: Brain ischemia and reperfusion molecular mechanisms of neuronal injury. J Neurol Sci 2000;179:1-33.

23 Nguyen DN, Spopen H, Su F, Schiettecatte J, Shi L, Hachimi-Idrissi S, Huyghens L: Elevated levels of S-100 beta protein and neuron-specific enolase associated with brain injury in patients with severe sepsis and septic shock. Crit Care Med 2006;34:19671974.

24 Davenport A: Neurogenic pulmonary oedema post-hemodialysis. NDT Plus 2008;1:4144

25 Brouns R, De Deyn PP: Neurological complications in renal failure: a review. Clin Neurol Neurosurg 2004;107:1-16.

26 Davenport A, Goel S, Mackenzie JC: Neurotoxicity of acyclovir in patients with endstage renal failure treated with continuous ambulatory peritoneal dialysis (CAPD). Am J Kidney Dis 1992;20:647-649.

27 Davenport A, Davison AM, Will EJ, Newton KE, Toothill C: Aluminium mobilisation following renal transplantation and the possible effect on susceptibility to bacterial sepsis. Quart J Med 1991;289:407-423.

28 Davenport A, Bramley PN: Cerebral function analyzing monitor and visual evoked potentials as a noninvasive method of detecting cerebral dysfunction in patients with acute hepatic and renal failure treated with intermittent machine hemofiltration. Ren Fail 1993;15:515-522.

29 Vanholder R, De Smet R, Glorieux G, Argiles A, Baurmeister U, Brunet P, Clark W, Cohen G, De Deyn PP, Deppisch R, Scamps-Latscha B, Henle T, Jorres A, Lemke HD, Massy ZA Passlick-Deetjen J, Rodriguez M, Stegmayr B, Stenvinkel P, Tetta C, Wanner C, Zidek W: Review on uremic toxins: classification, concentration, and interindividual variability. Kidney Int 2003;63:1934-1943.

30 De Deyn PP, D’Hooge R, Van Bogaert PP, Marescau B: Endogenous guanidino compounds as uremic neurotoxins. Kidney Int Suppl 2001;78:S77-S83.
31 Burn DJ, Bates D: Neurology and the kidney. J Neurol Neurosurg Psychiatry 1998;65:810821.

- 32 Griva K, Newman SP, Harrison MJ, Hankins M, Davenport A, Hansraj S, Thompson D: Acute neuropsychological changes in hemodialysis and peritoneal dialysis patients. Health Psychol 2003;22:570-578.

-33 Hanly PJ, Pierratos A: Improvement of sleep apnea in patients with chronic renal failure who undergo nocturnal hemodialysis. N Engl J Med 2001;344:102-107.

34 Pierratos A: Daily nocturnal home hemodialysis: nine years later. Hemodial Int 2004;8: 45-50.

35 Griva K, Hansraj S, Thompson D, Jayasena D, Davenport A, Harrison M, Newman SP: Neuropsychological performance after kidney transplantation: a comparison between transplant types and in relation to dialysis and normative data. Nephrol Dial Transplant 2004;19:1866-1874.

36 Griva K, Ziegelmann JP, Thompson D, Jayasena D, Davenport A, Harrison M, Newman SP: Quality of life and emotional responses in cadaver and living related renal transplant recipients. Nephrol Dial Transplant 2002;17:2204-2211.

37 Goodkin DA, Bragg-Gresham JL, Koening KG, Wolfe RA, Akiba T, Andreucci VE, Saito A, Rayner HC, Kurokawa K, Port FK, Held PJ, Young EW: Association of comorbid conditions and mortality in hemodialysis patients in Europe, Japan and United States: The Dialysis Outcomes and Practice Patterns Study (DOPPS). J Am Soc Nephrol 2003;14:3270-3277.

- 38 Van der Sande FM, Hermans MM, Leunissen KM, Kooman JP: Noncardiac consequences of hypertension in hemodialysis patients. Semin Dial 2004;17:304-306.

39 Davenport A, Cox C, Thuraisingham R: Achieving blood pressure targets during dialysis improves control but increases intradialytic hypotension. Kidney Int 2008; 73 : 759-764.

40 Lass P, Buscombe JR, Harber M, Davenport A, Hilson AJ: Cognitive impairment in patients with renal failure is associated with multiple-infarct dementia. Clin Nucl Med 1999;24:561-565

41 Dguchi T, Isazaki K, Yousuke K, Terasaki T, Otagiri M: Involvement of organic anion transporter on the efflux of uremic toxins across the blood brain barrier. J Neurochem 2006;96:1051-1059.

42 Davenport A: Practical guidance for dialyzing a hemodialysis patient following acute brain injury. Hemodial Int 2008;12:307312 . 
43 Provhovnik I, Post J, Uribarri J, Lee H, Sandu O, Langhoff E: Cerebrovascular effects of hemodialysis in chronic kidney disease. J Cereb Blood Flow Metab 2007;27:1861-1869.

44 Stefanidis I, Bach R, Mertens PR, Liakopoulos V, Liapi G, Mann H, Heintz B: Influence of hemodialysis on the mean blood flow velocity in the middle cerebral artery. Clin Nephrol 2005;64:129-137.

-45 Davenport A: Renal replacement therapy in the patient with acute brain injury. Am J Kidney Dis 2001;37:457-466.

46 Davenport A: Intradialytic complications during hemodialysis. Hemodial Int 2006;10: 162-167.
7 Alfrey AC, LeGendre GR, Kaehny WD: The dialysis encephalopathy syndrome. Possible aluminium intoxication. N Engl J Med 1976; 294:184-189.

48 Dunea G: Dialysis dementia: an epidemic that came and went. ASAIO 2000;47:192194.

49 Garrido RS, Aguado JM, Díaz-Pedroche C, Len O, Montejo M, Moreno A, Gurguí M, Torre-Cisneros J, Pareja F, Segovia J, Garcia M, Lumbreras C: A review of critical periods for opportunistic infection in the new transplantation era. Transplantation 2006; 82:1457-1462.
50 Chen Y, Trofe J, Gordon J, Autissier P, Woodle ES, Koralnik IJ: BKV and JCV large T antigen-specific CD8(+) $\mathrm{T}$ cell response in HLA A*0201(+) kidney transplant recipients with polyomavirus nephropathy and patients with progressive multi-focal leukoencephalopathy. J Clin Virol 2008;42:198202.

51 Takada M, Nadeau KC, Hancock WW, Mackenzie HS, Shaw GD, Waaga AM, Chandraker A, Sayegh MH, Tilney NL: Effects of explosive brain death on cytokine activation of peripheral organs in the rate. Transplantation 1998;65:1533-1542.

52 Pratschke J, Tullius SG, Neuhaus P: Brain death associated ischemia/reperfusion injury. Ann Transplant 2004;9:78-80. 